\title{
ASSESSING THE USE OF FOLLOW-UP SKELETAL SURVEYS IN CHILDREN WITH SUSPECTED PHYSICAL ABUSE
}

by

\section{Ranjodh Singh}

Submitted to the Graduate Faculty of the

School of Medicine in partial fulfillment

of the requirements for the degree of

Bachelor of Philosophy

University of Pittsburgh

2010 


\title{
UNIVERSITY OF PITTSBURGH
}

\author{
University Honors College
}

This thesis was presented

by

\section{Ranjodh Singh}

It was defended on

23 April 2010

and approved by

Janet Squires, MD, Department of Pediatrics

Noel Zuckerbraun, MD, Department of Emergency Medicine

Ashok Panigrahy, MD, Department of Radiology

Thesis Director: Rachel Berger, MD, MPH, Department of Pediatrics 
Copyright $($ C by Ranjodh Singh

2010 


\title{
ASSESSING THE USE OF FOLLOW-UP SKELETAL SURVEYS IN CHILDREN WITH SUSPECTED PHYSICAL ABUSE
}

\author{
Ranjodh Singh \\ University of Pittsburgh, 2010
}

Background: A follow-up SS (FSS) can provide additional clinical data in a subset of children that undergo an initial skeletal survey (ISS) for the evaluation of physical abuse. Three studies suggested that $33-57 \%$ of FSS identify additional fractures, but the study populations were small and highly selective.

Objective: To assess a consecutive study sample of children who underwent an ISS and FSS, to evaluate the results of the ISS and FSS, and to calculate the proportion in whom clinical diagnosis depended on the FSS results.

Methods: This was a retrospective, descriptive study of children who had an ISS and FSS at Children's Hospital of Pittsburgh of UPMC from 4/1/02 to 3/31/09. Data were collected about demographics, reason for and results of ISS and FSS, the interval in days between ISS and FSS, and whether the FSS affected clinical diagnosis.

Results: During the 7-yr study period, 1470 children underwent an ISS. Eleven percent (169/1470) of these children also underwent a FSS. These 169 children made up the subjects of the study. The FSS identified 39 fractures in 16\% (27/169) of the study subjects. All 39 fractures were rib, metaphyseal or metacarpal. The identification of new fractures on FSS led a definite diagnosis of abuse in $7.6 \%$ (7/92) of the subjects who did not have a previous diagnosis. These 7 subjects were all less than a year of age. The ISS identified no fractures in $43 \%$ (3/7) of these subjects. A total of 29 fractures that were felt to be equivocal of ISS were confirmed as normal 
variants on FSS.

Conclusions: This is the largest study to evaluate the use of FSS. The proportion of subjects with additional fractures identified on FSS was lower than in previous studies. The FSS made a definite diagnosis of abuse in $\sim 8 \%$ of subjects. A large number of equivocal fractures on ISS were felt to be normal variants on FSS. Future studies will compare children who only receive an ISS with those who receive an ISS and FSS to identify characteristics that, when present in a child undergoing an ISS, also warrant a FSS. 


\section{TABLE OF CONTENTS}

ACKNOWLEDGMENTS ............................................................................................................... $\mathrm{X}$

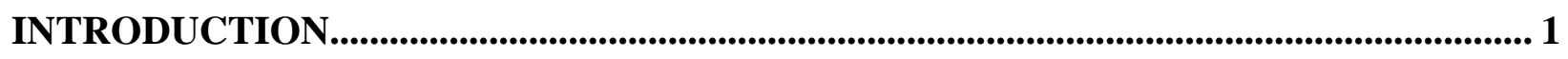

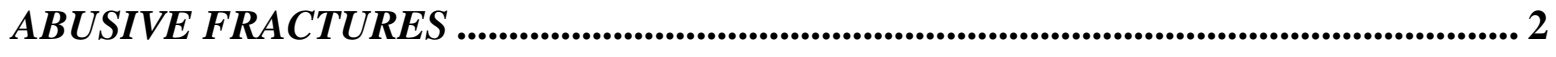

THE SKELETAL SURVEY ............................................................................................. 3

THE FOLLOW-UP SKELETAL SURVEY ......................................................................... 6

CURRENT STUDY: GOALS, OBJECTIVES AND HYPOTHESES ................................. 10

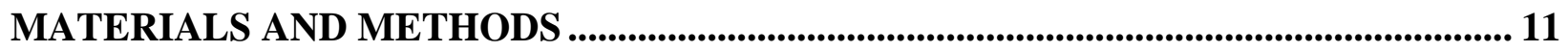

STUDY DESIGN AND SUBJECTS ............................................................................ 11

DEFINITIONS ........................................................................................................................................ 12

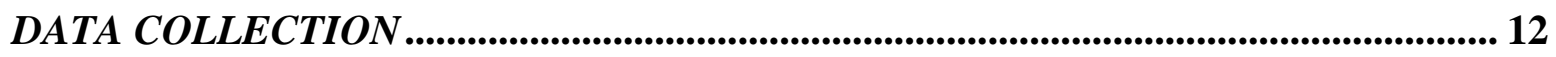

DATA ANALYSIS .............................................................................................................................. 14

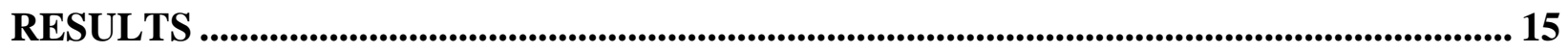

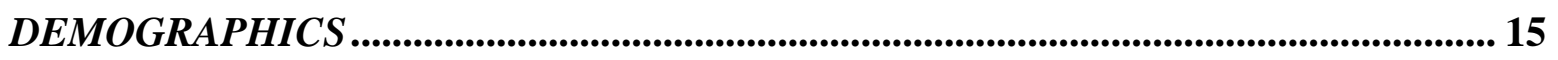

RESULT OF INITIAL SKELETAL SURVEY AND ASSESSMENT OF ABUSE .......... 16

RESULT OF FOLLOW-UP SKELETAL SURVEY .............................................................. 17

EQUIVOCAL FRACTURES ON INITIAL SKELETAL SURVEY.................................. 17

EFFECT OF FOLLOW-UP SKELETAL SURVEY ON THE CLINICAL DIAGNOSIS

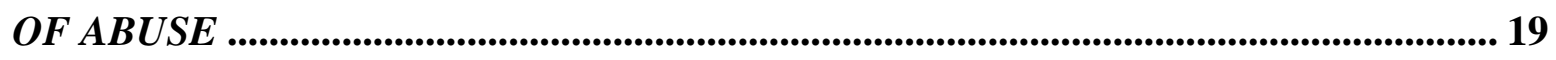


DISCUSSION …….................................................................................................................................... 21

USE OF FOLLOW-UP SKELETAL SURVEY IN DIAGNOSIS OF CHILD PHYSICAL

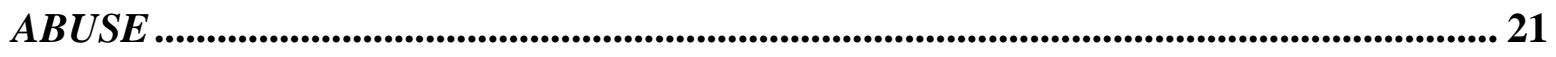
EVALUATION OF EQUIVOCAL FRACTURES ON FOLLOW-UP SKELETAL

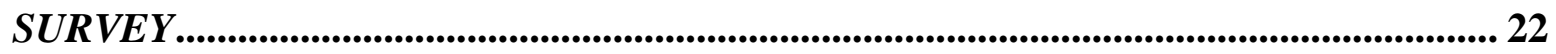

THE POTENTIAL USE OF FOLLOW-UP SKELETAL SURVEY IN CONTACT

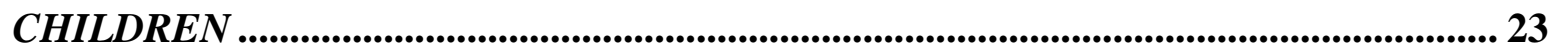

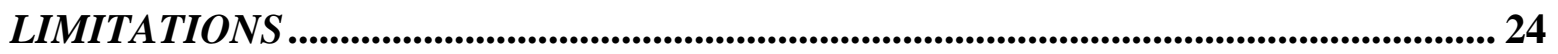

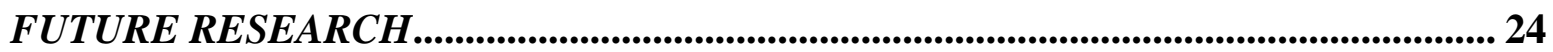

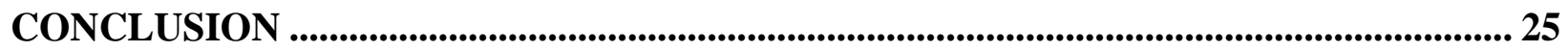

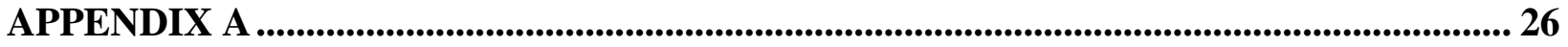

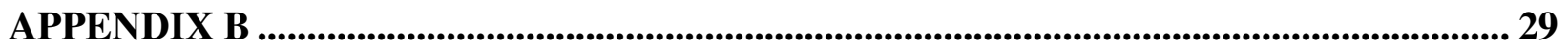

BIBLIOGRAPHY …..................................................................................................................... 34 


\section{LIST OF TABLES}

Table 1: Fatalities due to child maltreatment (2007) ………...................................................... 1

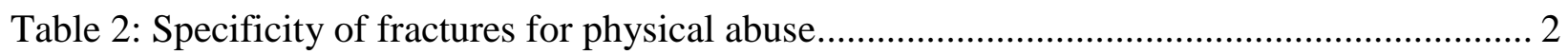

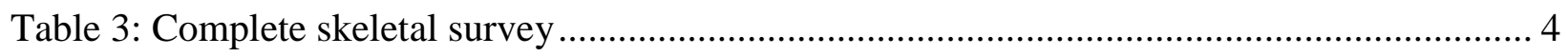

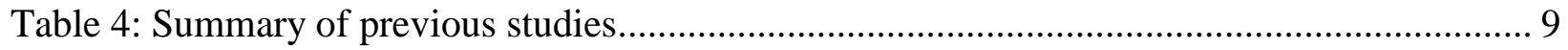

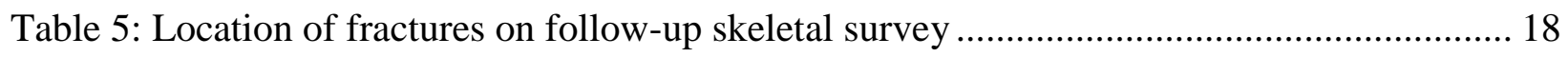

Table 6: Type of fractures on follow-up skeletal survey ...................................................... 18

Table 7: Subjects in whom the findings of follow-up skeletal survey led to a definite diagnosis of

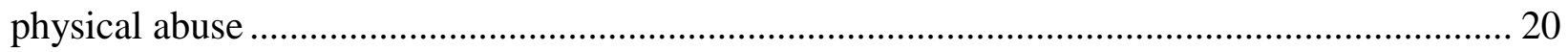




\section{LIST OF FIGURES}

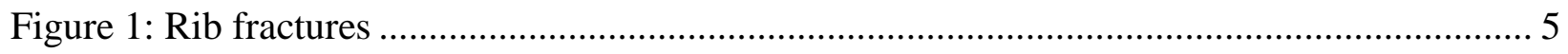

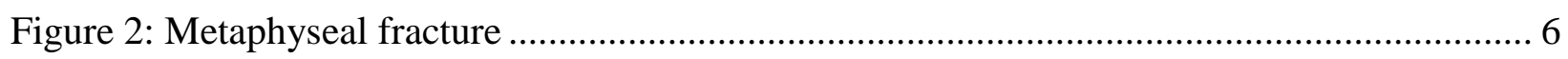

Figure 3: Proportion of children who had an initial skeletal survey and follow-up skeletal survey

Figure 4: Assessment of abuse after initial skeletal survey ............................................. 16

Figure 5: Assessment of abuse after follow-up skeletal survey........................................... 19 


\section{ACKNOWLEDGMENTS}

I wish to thank Dr. Janet Fromkin for her help in revising the research paper that led to this

thesis. I wish to thank Ms. Shanna Duffy, for without her original research, this project would not have been possible. Special thanks to Drs. Janet Squires, Noel Zuckerbraun, and Ashok Panigrahy for serving on the thesis committee. I also wish to thank Drs. James Lennox and Edward Stricker for supporting my Bachelor of Philosophy degree application. Foremost, I wish to thank Dr. Rachel Berger for allowing me to work on one her many projects. Without Dr.

Berger dedicated support and auspicious guidance, this project would have never taken form. 


\section{INTRODUCTION}

In $2007,794,000$ children were victims of child maltreatment. Physical abuse was the third leading cause of maltreatment, accounting for over 85,000 of the victims. ${ }^{1}$ While physical abuse only accounted for $10.8 \%$ of the total cases of maltreatment, it was responsible for at-least $26.4 \%$ of the fatalities (Table 1). Since physical abuse was a part of multiple maltreatments, it is possible that physical abuse was a contributor in over $62 \%$ of the fatalities.

Table 1: Fatalities due to child maltreatment (2007)

\begin{tabular}{|c|c|c|}
\hline Maltreatment Type & Number & Percent \\
\hline Medical Neglect & 15 & 1.2 \\
\hline Multiple Maltreatment Types & $\mathbf{4 5 1}$ & $\mathbf{3 5 . 2}$ \\
\hline Neglect & 437 & 34.1 \\
\hline Other & 26 & 2.0 \\
\hline Physical Abuse & $\mathbf{3 3 8}$ & $\mathbf{2 6 . 4}$ \\
\hline Psychological Abuse & 1 & 0.1 \\
\hline Sexual Abuse & 3 & 0.2 \\
\hline Unknown & 9 & 0.7 \\
\hline Total & $\mathbf{1 , 2 8 0}$ & - \\
\hline Percent & - & 99.9 \\
\hline
\end{tabular}


Fractures are a common manifestation of child physical abuse. ${ }^{2}$ Leventhal and colleagues showed that in children less than a year of age, over $60 \%$ of rib and radius/ulna fractures were attributable to abuse. ${ }^{3}$ While all unsuspected skeletal injuries in infants and young children without underlying genetic or endocrine abnormalities should prompt concern, certain fractures are more specific for abuse than others (Table 2). ${ }^{4}$ Several previous studies have described the distribution of fractures in physically abused children. ${ }^{5-8}$ In infants, rib and metaphyseal fractures predominate. In children older than a year, long bone fractures are the most common of skeletal injuries due to abuse.

Table 2: Specificity of fractures for physical abuse

High specificity

Classic metaphyseal lesion

Rib fractures, especially bilateral

Scapular fractures

Spinous process fractures

Sternal fractures

\section{Moderate specificity}

Multiple fractures, especially bilateral

Fractures of different ages

Epiphyseal separation

Vertebral body fractures and subluxations

Digital fractures

Complex skull fractures

\section{Common but low specificity}

Subperiosteal new bone formation

Clavicular fractures

Long bone shaft fractures

Linear skull fractures 
Diagnosing fractures in infants and young children can be challenging. Infants are non-verbal and therefore cannot provide a history of the injury. Infants are also non-ambulatory so injury cannot be detected from impaired motor movement. While abusive fractures are rarely fatal, the early recognition of child abuse cannot be overemphasized. If abusive fractures are not identified, a child may unknowingly be discharged to a violent environment and placed at a significantly increased risk of repeated injury. Previous studies have reported acute and/or healing fractures on postmortem evaluation in abused children. In a study by King and colleagues, $24 \%(9 / 37)$ of children who died from abuse had healing fractures. ${ }^{5}$ Oral and colleagues found that $7.5 \%$ (3/38) children with fatal abusive head trauma had previous sign of physical abuse which were missed by medical staff. ${ }^{9}$

THE SKELETAL SURVEY

The skeletal survey (SS) is an important screening tool for identifying unsuspected fractures in infants and young children. ${ }^{6,10}$ A SS is a series of $\mathrm{x}$-ray images of all bones in the body in one, often two, anatomical views. The American Academy of Pediatrics (AAP) recommends the following views for the SS (Table 3): ${ }^{11}$ 
Table 3: Complete skeletal survey

\begin{tabular}{ll} 
Skeleton & Views \\
\hline Appendicular & Arms (AP) \\
& Forearms (AP) \\
& Hands (PA) \\
& Thighs (AP) \\
& Legs (AP) \\
& Feet (PA or AP) \\
& Thorax (AP and lateral), to include thoracic spine and ribs \\
& AP abdomen, lumbosacral spine, and bony pelvis \\
& Lumbar spine (lateral) \\
& Cervical spine (AP and lateral) \\
& Skull (frontal and lateral)
\end{tabular}

AP indicated anteroposterior; PA, posteroanterior

Previous studies have demonstrated that the SS is an important tool in recognizing unsuspected fractures in the evaluation of child abuse. In a study by Merten and colleagues, the SS identified unsuspected fractures in 33\% (186/563) of abused infants and children. ${ }^{12}$ In a similar study, Belfer and colleagues reported that 26\% (25/96) of children suspected of physical abuse had a SS which recognized unsuspected fractures. ${ }^{13}$ Day and colleagues showed similar findings: $24 \%$ (17/76) of children suspected of physical abuse had a SS which identified new fractures. ${ }^{14}$

In support of these studies, the 2009 AAP policy statement recommends that, "A [SS] is mandatory in all cases of suspected physical abuse in children younger than 2 years...the screening [SS] or bone scan has little value in children older than 5 years. Decisions about which types of imaging to perform in the 2-to 5-year-old age group must be made individually on the basis of the specific clinical indicators of abuse."11 
While previous studies confirm the importance of the SS in recognizing unsuspected fractures, ${ }^{12-}$ ${ }^{14}$ some fracture are not consistently identified on the SS. Rib (Figure 1) and metaphyseal (Figure 2) fractures, both which are highly specific for physical abuse, ${ }^{4}$ are difficult to detect when acute and can be missed on an initial SS (ISS). ${ }^{13,15-16}$

Figure 1: Rib fractures

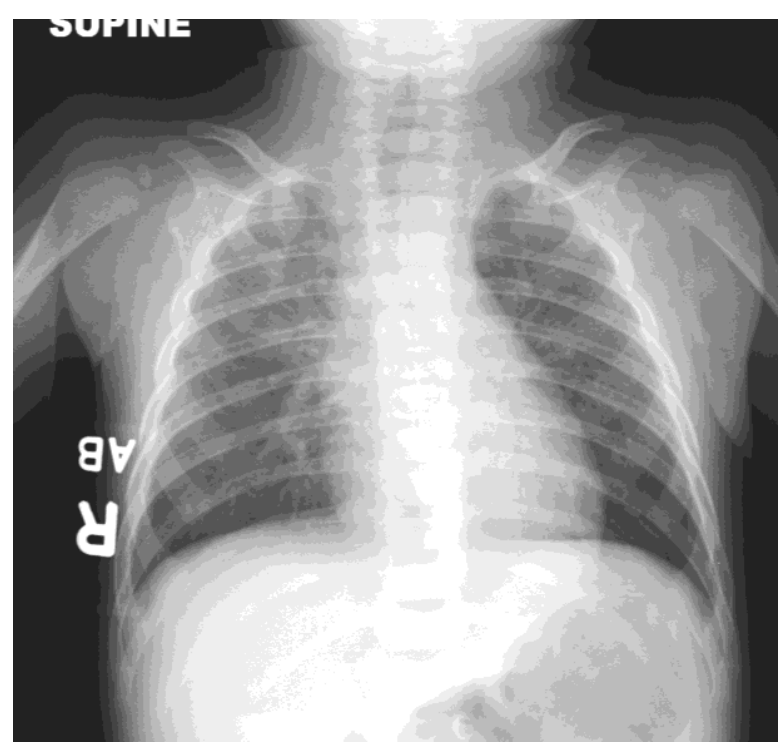

The acute rib fractures are not visible

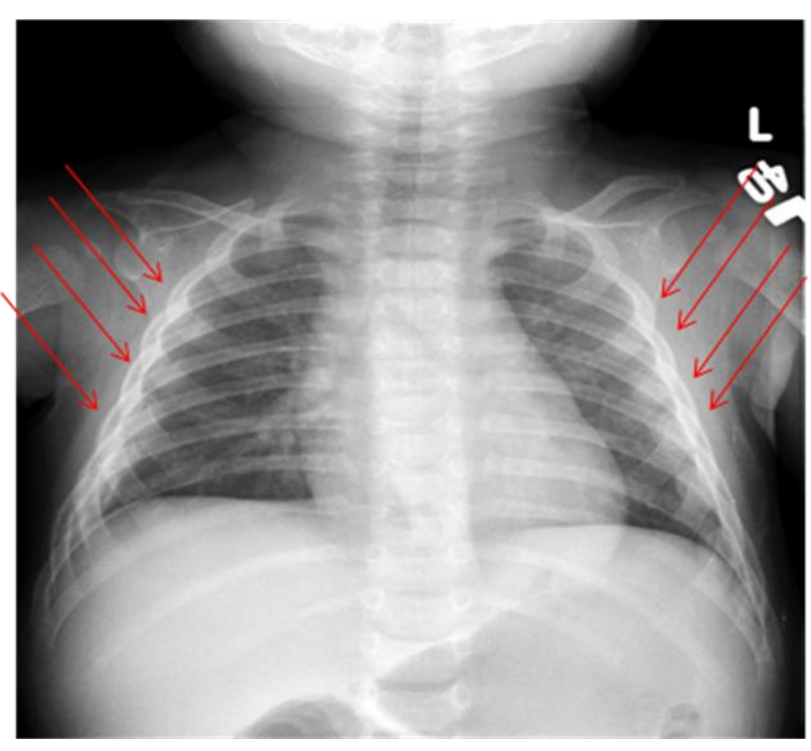

In the same film obtained 2 weeks after the ISS, the rib fractures are clearly visualized (see arrows) 
Figure 2: Metaphyseal fracture

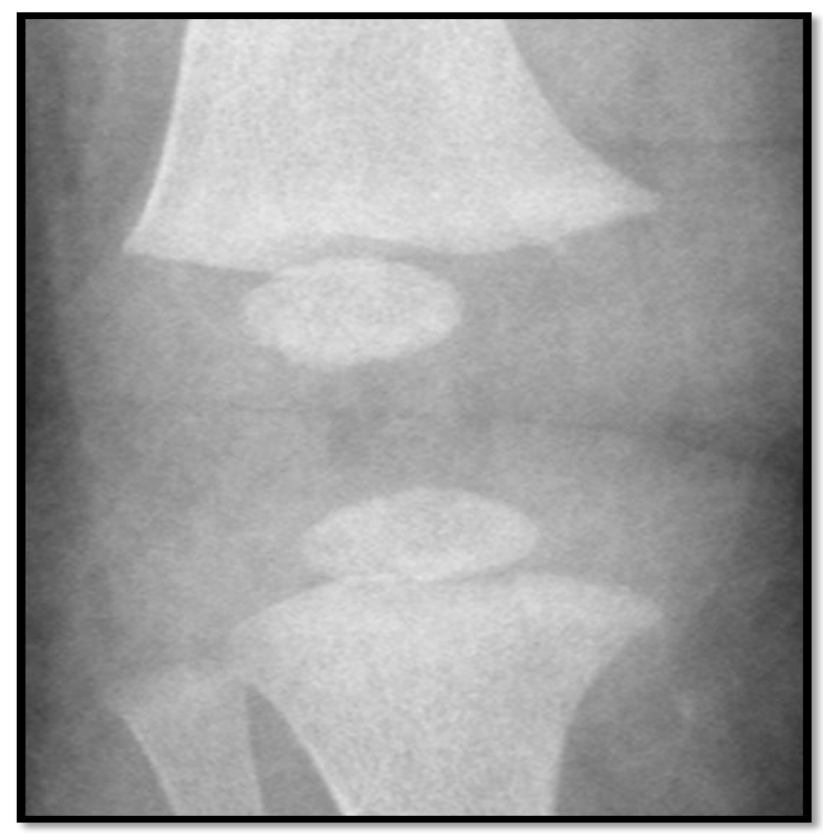

No evidence of a metaphyseal fracture

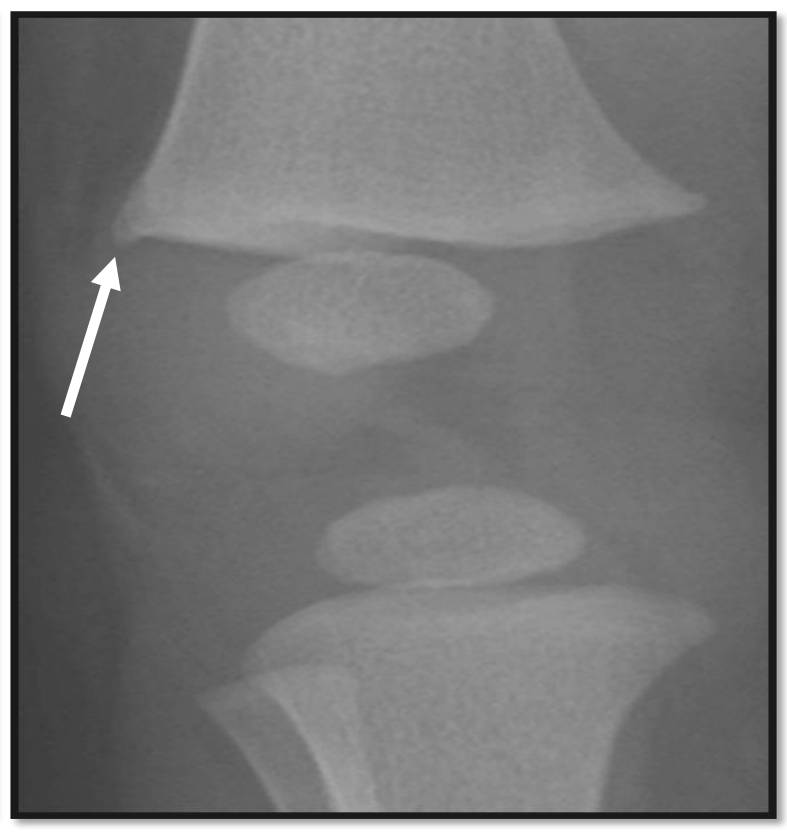

In the same film obtained 2 weeks after the ISS, the metaphyseal fracture of the femur is clearly visible (see arrow)

THE FOLLOW-UP SKELETAL SURVEY

Because of this limitation of the ISS, three notable studies have assessed the use of the follow-up SS (FSS) in child physical abuse evaluation. In a small study involving 23 children, Kleinman and colleagues prospectively obtained a FSS in children in whom the diagnosis of physical abuse was strongly suspected. ${ }^{17}$ The mean age (range) of their subjects was 9 months $(1$ week -35 months). In all these subjects, the ISS identified at least one fracture. The FSS identified fractures in 57\% (13/23) of the subjects. Nineteen fractures were identified: 8 ribs, 8 
metaphyseal, 1 vertebra, 1 sacrum and 1 metacarpal. From these data, the authors concluded that, “A [FSS] performed approximately 2 weeks after the [ISS] appears to provide additional information regarding the number, character and age of injuries inflicted on infants and toddlers." 17

In support of the findings of Kleinman and colleagues, the APP for the first time included a recommendation for a FSS in their 2000 policy statement: "Recent evidence suggests that a [FSS] approximately 2 weeks after the [ISS] increases the diagnostic yield, and this procedure should be considered when abuse is strongly suspected."18

In the second study to evaluate the use of the FSS, Zimmerman and colleagues used the same inclusion criteria as the Kleinman study and had a similar study population. ${ }^{19}$ The FSS identified fractures in $33 \%(16 / 48)$ of subjects. Thirty-five fractures were identified: 18 ribs, 4 metaphyseal, 4 scapular, 1 tibular, 2 fibular, 1 ulnar, 3 vertebrae and 2 clavicular. In addition, there were 21 equivocal fractures on ISS which were later determined to be normal variants on FSS. The findings of the FSS led to a definite diagnosis of abuse in 4.2\% (2/48) of subjects. Zimmerman and colleagues concluded by recommending that, "a [FSS] should be completed on all patients who have an [ISS] performed for suspected physical abuse and for whom child abuse is still a concern." The recommendation by Zimmerman and colleagues was broader than the recommendation by Kleinman and colleagues, encompassing all children that underwent an ISS. Also, the data did not support the recommendation because Zimmerman and colleagues used a strong enrollment bias, only including children in whom abuse was strongly suspected. An accompanying editorial supplemented the conclusion of the Zimmerman study by stating: "I 
agree with the authors that any child who warrants an [ISS] should also have a [FSS] completed." 20

In the largest study to assess the use of FSS, Harlan and colleagues included all children less than 3 years of age who underwent an ISS and FSS between 10-21 days of one another. A total of 101 children met the inclusion criteria. In this study, 38\% (38/101) of the subjects had FSS that identified a total 60 new fractures. From these fractures, there were 40 rib fractures, 3 upper extremity fractures, 12 lower extremity fractures, 4 metatarsal fractures and 1 vertebra fracture. These new findings modified the diagnosis of abuse in $8.9 \%(9 / 101)$ of subjects; the authors did not explain whether this meant that the diagnosis of abuse was made after FSS or that the concern for abuse was decreased. In addition, there were 14 fractures which were felt to be equivocal on ISS but were later determined to be normal variants on FSS. Harlan and colleagues concluded that, "...the [FSS] is an important part of the medical evaluation of suspected child abuse. $" 21$

Previous studies that have assessed the use of the FSS were limited and strongly selective. These studies usually only included children in whom there were abnormal findings on the ISS and/or children in whom the diagnosis of physical abuse was strongly suspected. These studies also generally failed to mention the total number of children who received an ISS without a FSS. Not surprisingly, in all these studies, a high proportion of children had FSS that identified fractures (Table 4). 
Table 4: Summary of previous studies

\begin{tabular}{|l|l|l|l|}
\hline & Kleinman et al (1996) & Zimmerman et al (2005) & Harlan et al (2009) \\
\hline Sample size & 23 & 48 & 101 \\
\hline Proportion with new fractures on FSS & $57 \%$ & $33 \%$ & $38 \%$ \\
\hline Number of fractures identified on FSS & 19 & 35 & 60 \\
\hline Description of new fractures & $\begin{array}{l}\text { Majority rib and } \\
\text { metaphyseal }\end{array}$ & $\begin{array}{l}\text { Majority rib and } \\
\text { metaphyseal }\end{array}$ & Majority rib \\
\hline $\begin{array}{l}\text { Effect of FSS result on the assessment } \\
\text { of abuse }\end{array}$ & $\begin{array}{l}\text { Did not look at this } \\
\text { outcome }\end{array}$ & $\begin{array}{l}\text { FSS made diagnosis of } \\
\text { abuse in 2/48 (4.2\%) }\end{array}$ & $\begin{array}{l}\text { Diagnosis of abuse } \\
\text { modified in 9/101 } \\
\text { (8.9\%) }\end{array}$ \\
\hline
\end{tabular}

In 2009, the AAP modified its 2000 FSS recommendation to support the findings of Zimmerman and colleagues. The 2009 AAP policy recommended that a FSS should be performed approximately two weeks after the ISS in cases "when abnormal or equivocal findings are found on [ISS] and when abuse is suspected on clinical grounds." ${ }^{\prime 1}$ The 2009 AAP policy made the FSS an important component of the clinical practice of evaluating children in whom abuse is suspected.

While the 2009 policy statement expands the use of the FSS, one problem with the recommendation is that it is vague on what is meant by “... when abuse is suspected on clinical grounds." 'Suspected abuse' may vary significantly and is often based on a clinician's individual experiences and background. Not surprisingly, studies show that two clinicians taking care of patients with identical histories and physical exams may reach completely different conclusions on whether they 'suspect' abuse on clinical grounds ${ }^{22-24}$ and therefore whether a FSS is warranted. 
The goals of the current study were to expand on previous literature and assess the use of the FSS by evaluating a large consecutive sample of children who underwent both ISS and FSS at Children's Hospital of Pittsburgh (CHP) of UPMC. The objectives of the study were: (1) to calculate the proportion of children who underwent both an ISS and FSS; (2) to determine the results of ISS and FSS in children who had both; (3) to evaluate the proportion and characteristics of patients in whom the clinical diagnosis was changed by the results of the FSS. We hypothesized that (1) there would be a subset of children with no fractures on ISS in whom the FSS would reveal fractures and a diagnosis of abuse would be dependent on the FSS, and that (2) a significant proportion of children with equivocal fractures on ISS would be recognized as having normal variants on FSS and in these children, the concern for abuse would be decreased as a result of the FSS. 


\section{MATERIALS AND METHODS}

STUDY DESIGN AND SUBJECTS

This was a retrospective, descriptive study approved by the Institutional Review Board at the University of Pittsburgh with a waiver of informed consent. Children were eligible for the study if they had an ISS billed to their medical record between 4/1/02-3/31/09. The electronic medical record of each eligible child was reviewed to determine whether the ISS was for the evaluation of trauma and whether the patient also had a FSS. Children with an ISS not performed for the evaluation of trauma were excluded. Children with only an ISS performed for trauma were included to determine the proportion of all children that underwent both ISS and FSS. No information was collected about these children except for the fact that they only had an ISS.

The ISS performed routinely at CHP complies with the American College of Radiology (ACR) and AAP recommendations. ${ }^{11,25}$ The FSS performed at CHP is identical to the ISS, except that views of the skull and spine are excluded. Skull and spine views are excluded because recent studies show that views of the chest, lower extremities and upper extremities are equally as sensitive as a full FSS in identifying fractures. ${ }^{21,26}$ The FSS also routinely excludes oblique views of the ribs. 


\section{DEFINITIONS}

A 'previously recognized fracture' was defined as a fracture that was diagnosed prior to the ISS. A 'positive ISS' was defined as a SS that identified any fractures, including those that were previously recognized. A 'positive FSS' was defined as a SS that identified new fractures or confirmed equivocal fracture from ISS as definite fractures. A 'negative FSS' was defined as a SS that identified no new fractures or confirmed equivocal fractures from ISS as normal variants. Clinical diagnosis of abuse was defined as (1) definite (2) probable (3) possible and (4) not abuse, as assessed by the Child Protection Team (CPT) at CHP, a commonly used gold-standard for defining and assessing abuse. ${ }^{27-29}$

\section{DATA COLLECTION}

The following data was collected on each subject using electronic medical records: age at time of ISS in months, gender, 'reason for ISS,' number of days between ISS and FSS, results of ISS and FSS and assessment of the clinical diagnosis of abuse after ISS and after FSS. Race and insurance information was unavailable.

Possible 'reason for ISS' was: (1) 'previously recognized fractures' (2) features of child abuse (e.g. bruising) (3) suspected abusive head injury (AHT) (4) signs or symptoms of injury (e.g. swelling) (5) non-specific symptoms (e.g. fussiness) (6) social concerns (e.g. abused sibling) (7) acute life threatening event (ALTE) (8) death (9) other. These categories were derived through an iterative process as part of a related study at $\mathrm{CHP} .{ }^{30}$ The 'reason for ISS' was determined by 
two data extractors by referencing the emergency department notes and CPT notes. In children with more than one 'reason for ISS,' the reason which prompted the most concern for abuse (e.g. multiple bruises in an infant with vomiting) was documented. Suspected AHT was documented as the 'reason for ISS' only if an abnormal result on neuroimaging was obtained prior to the ISS.

The assessment of abuse made by the CPT was used to determine the clinical diagnosis of abuse after the ISS and after the FSS. These two diagnoses were compared to determine whether the results of the FSS influenced and/or altered the initial clinical diagnosis of abuse. Consult notes by the CPT that detailed the assessment of abuse after ISS were available on all subjects. In most cases, these notes also contained addendums which explained the CPT assessment of abuse after FSS. In the very few cases where the assessment of abuse after FSS was not detailed by the CPT, senior author, Rachel Berger MD, MPH, made the assessment in subjects with a positive FSS. This was subjective, though, limited to only a few cases.

Result of ISS and FSS were documented by assessing the location, type and age of each fracture. Possible locations of fractures were: (1) rib (2) skull (3) humerus (4) radius/ulna (5) femur (6) tibia/fibula or (7) other (e.g. hand, foot, spine and clavicle). Multiple rib fractures were considered a single fracture. Types of fractures were: (1) transverse/greenstick (2) spiral/oblique (3) subperiosteal elevation (4) metaphyseal (5) buckle, (6) rib or (7) unknown. Skull fractures were classified as unknown because we did not collect specific information on their various types (e.g. linear, depressed, diastatic, basilar, etc). Ages of fractures were either (1) acute (2) healing (3) acute and healing or (4) unknown. The age of skull fractures was always classified as unknown. Fractures were also either definite or equivocal based on the radiologist's reading. If 
the radiologist did not mention whether the fracture(s) was definite or equivocal, it was assumed that the fracture was definite. Original radiographs were not reinterpreted. When additional radiological films were obtained within 48 hours of the ISS and/or FSS, these films were counted as part of the ISS and/or FSS.

DATA ANALYSIS

SPSS 17.0 (SPSS Inc., Chicago, IL) was used for analyses. Descriptive statistics were used to describe the study population; chi-square was used to compare proportions. 


\section{RESULTS}

\section{DEMOGRAPHICS}

Between 4/1/02 and 3/31/09, 1470 children underwent an ISS for the evaluation of suspected physical abuse. Of these, 11\% (169/1470) also received a FSS. These 169 patients made up the subjects of the study. The median (range) age of the study subjects was 2 (0-33) months. Eightyeight percent (148/169) of the subjects were less than 12 months of age. The mean time (SD) in days between ISS and FSS was 19 (11). The mean (SD) number of FSS performed each year during the study period was $24(13)$. There was a significant increase $(\mathrm{p}<0.00)$ in the proportion of FSS performed in the last four years of the study (4/1/05-3/31/09) as compared to the first three years (4/1/02-3/31/05) (Figure 3).

Figure 3: Proportion of children who had an initial skeletal survey and follow-up skeletal survey

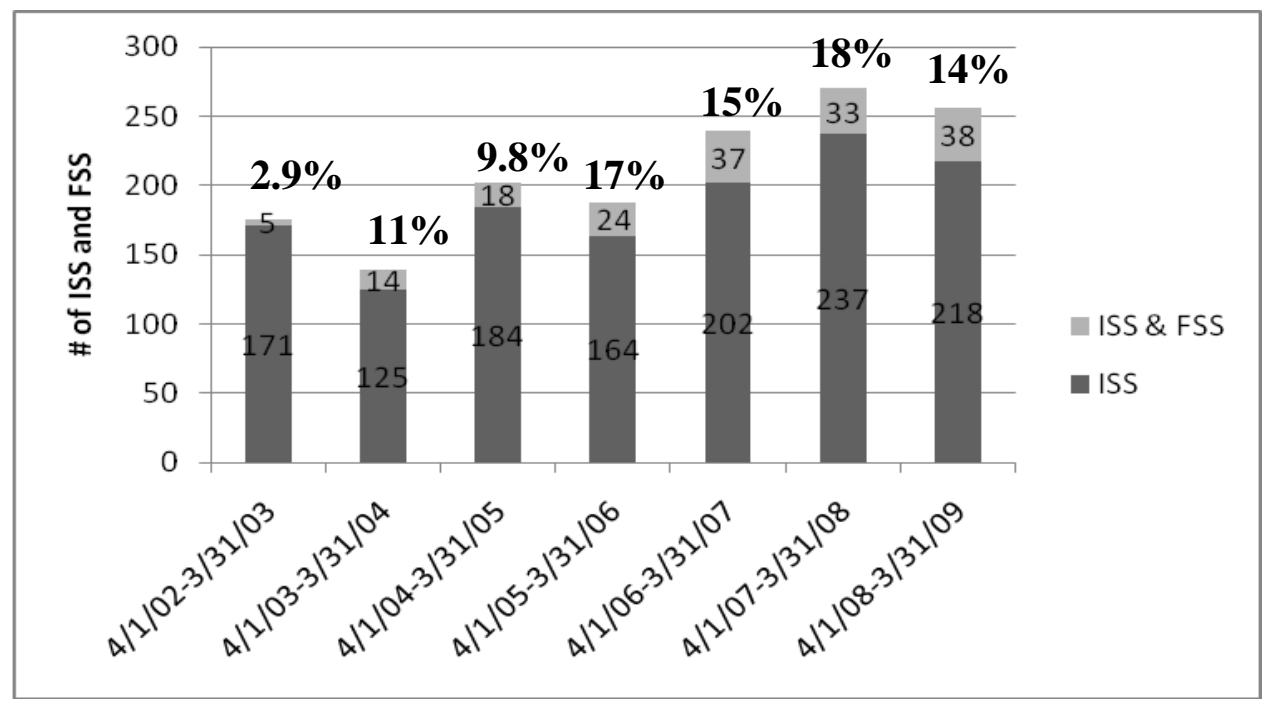


The most common reason for ISS among the 169 study subjects were 'previously recognized fracture(s)' (44\%) and suspected AHT (29\%). The ISS was positive in 76\% (128/169) of subjects, leading to a definite diagnosis of abuse in 37\% (63/169) of subjects. For subjects with a negative ISS, a definite diagnosis of abuse was made in $8.3 \%$ (14/169) based on clinical findings other than fractures (e.g. AHT, bruising) (Figure 4).

Figure 4: Assessment of abuse after initial skeletal survey

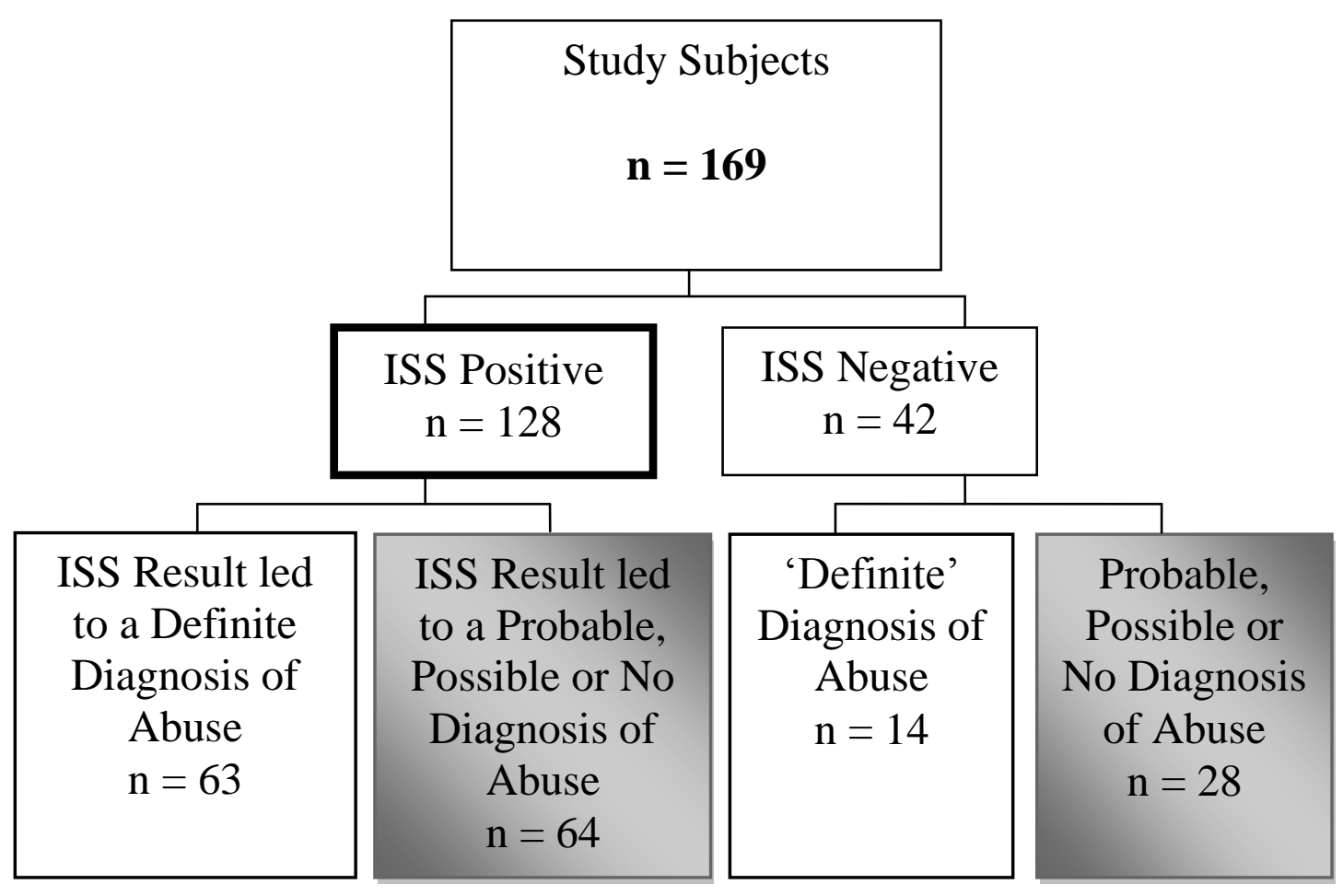


The FSS was positive in 16\% (27/169) of the study subjects. The median (range) age of these 27 subjects was 2 (1-33) months. Fifty-two percent (14/27) were females. Thirty-nine healing fractures were identified in these 27 subjects. Ninety two percent (36/39) of these fractures were not noted on ISS; the remaining $8 \%$ (3/39) were felt to be equivocal on ISS but determined to be definite fractures on FSS. Forty-four percent (17/39) of these fractures were in the ribs. Fiftyfour percent (21/39) were extremity fractures; the majority of these extremity findings were metaphyseal fractures or subperiosteal elevation. The FSS was negative in $84 \%(142 / 169)$ of the subjects. The median age (range) of these 141 subjects was identical to the 27 subjects with positive FSS. Forty-six percent (65/142) were female.

EQUIVOCAL FRACTURES ON INITIAL SKELETAL SURVEY

There were a total of 32 equivocal fractures on ISS. Nine percent (3/32) of these equivocal fractures were later determined to be definite fractures; 91\% (29/32) were determined to be normal variants. Seventy-nine percent (23/29) of the equivocal fractures confirmed as normal variants were in the extremities (Table 5); the type for the majority of equivocal fractures later confirmed as normal variants was metaphyseal (Table 6). 
Table 5: Location of fractures on follow-up skeletal survey

\begin{tabular}{llll}
\hline Location & $\begin{array}{l}\text { New } \\
\text { Fractures }\end{array}$ & $\begin{array}{l}\text { Confirmed } \\
\text { Fractures }\end{array}$ & $\begin{array}{l}\text { Normal } \\
\text { Variants }\end{array}$ \\
\hline Ribs & 15 & 2 & 3 \\
Skull & 0 & 0 & $2 *$ \\
Humerus & 2 & 0 & 2 \\
Radius/Ulna & 6 & 0 & 6 \\
Femur & 4 & 0 & 4 \\
Tibia/Fibula & 8 & 0 & 9 \\
Clavicle & 0 & 0 & 1 \\
Hand & 1 & 1 & 2 \\
\hline Total & $\mathbf{3 6}$ & $\mathbf{3}$ & $\mathbf{2 9}$ \\
$*$ One patient did have views of the skull on FSS
\end{tabular}

Table 6: Type of fractures on follow-up skeletal survey

\begin{tabular}{llll}
\hline Type & $\begin{array}{l}\text { New } \\
\text { Fractures }\end{array}$ & $\begin{array}{l}\text { Confirmed } \\
\text { Fractures }\end{array}$ & $\begin{array}{l}\text { Normal } \\
\text { Variants }\end{array}$ \\
\hline $\begin{array}{c}\text { Transverse/ } \\
\text { Greenstick }\end{array}$ & 0 & 0 & 0 \\
Spiral/Oblique 0 & & 0 \\
$\begin{array}{c}\text { Subperiosteal } \\
\text { Elevation }\end{array}$ & 6 & 0 & 0 \\
$\begin{array}{c}\text { Metaphyseal } \\
\text { Buckle }\end{array}$ & 12 & 0 & 0 \\
Rib & 15 & 0 & 12 \\
Unknown & 3 & 2 & 3
\end{tabular}


Prior to the FSS, 92 subjects did not have a definite diagnosis of abuse. Among these subjects, the FSS was positive and led to a definite diagnosis of abuse in 7.6\% (7/92) (Figure 5). In the 7 cases in which the FSS was critical in making a diagnosis of abuse, the FSS identified definite fractures (Table 7). In one subject with a positive FSS and without a definite diagnosis of abuse prior to FSS, the findings on FSS were equivocal and therefore did not change the diagnosis of abuse. Among the 84 patients with a negative FSS, the concern for abuse was lowered in one 16 month old male from 'probable' to 'possible' when rib fractures from ISS were interpreted as adrenal calcifications on FSS.

Figure 5: Assessment of abuse after follow-up skeletal survey

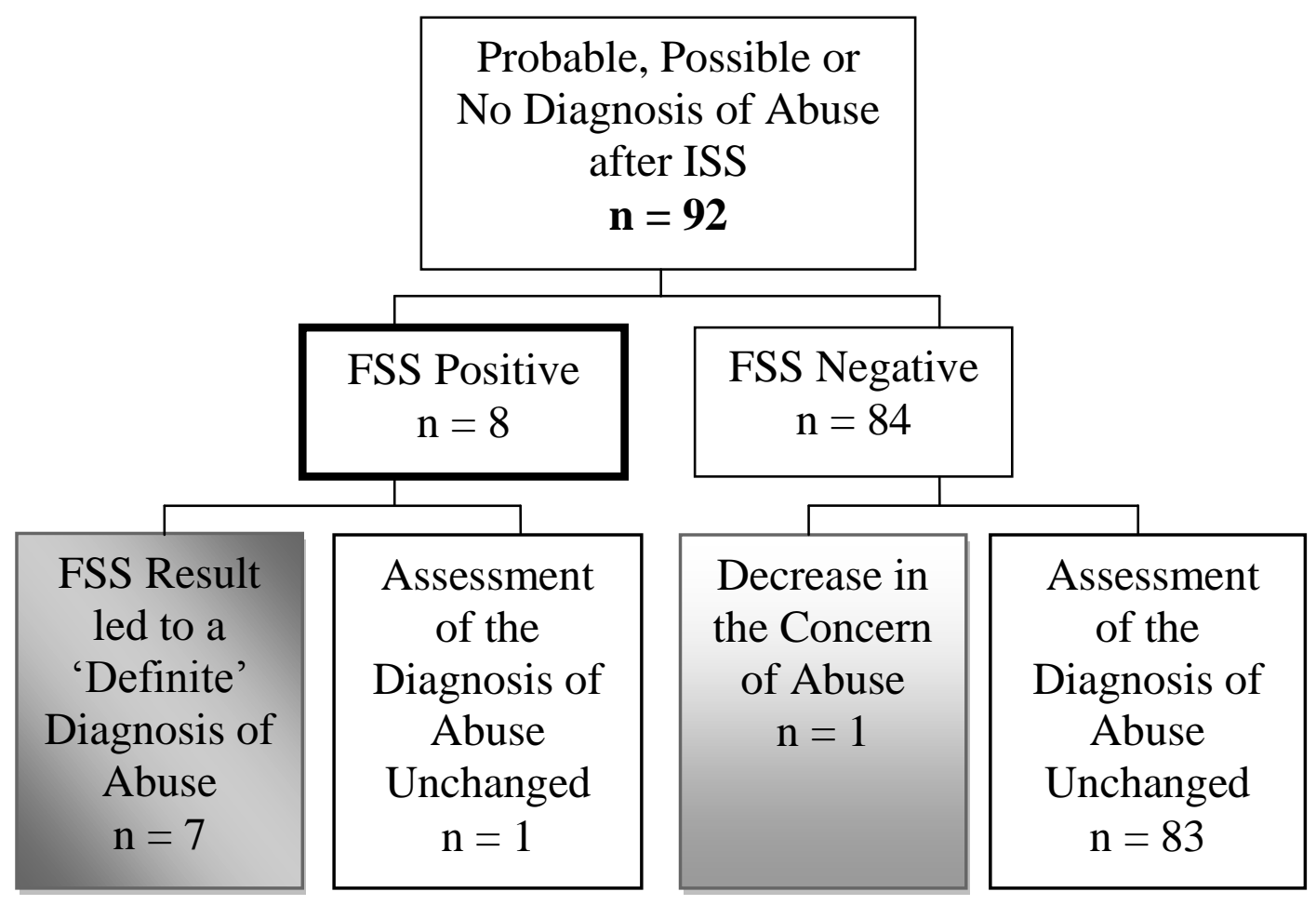


Table 7: Subjects in whom the findings of follow-up skeletal survey led to a definite diagnosis of physical abuse

\begin{tabular}{llllllll}
$\#$ & Age $(\mathbf{m o})$ & Gender & \multicolumn{2}{c}{ Reason for ISS } & Fx on ISS Abuse after ISS & \#days ISS $\rightarrow$ FSS & FSS (new fractures) \\
\hline 1 & 3 & Female & Bruises & No & Possible & 21 & $\begin{array}{l}12 \text { fxs (6 ribs*, } 3 \text { metaphyseal tibia, } 1 \text { subperiosteal } \\
\text { elevation humerus, } 1 \text { femur }\end{array}$ \\
2 & 2 & Female & Bruises & No & Probable & 21 & 7 rib fxs* \\
3 & 4 & Female & Skull fx & No new fxs & Possible & 18 & 8 fxs (7 ribs*, 1 metaphyseal femur) \\
4 & 7 & Female & Skull fx & No new fxs & Probable & 18 & 1 rib fx \\
5 & 2 & Male & Skull fx & No new fxs & Possible & 24 & 5 fxs (4 ribs*, 1 subperiosteal elevation femur) \\
6 & 10 & Female & Femur fx & No new fxs & Probable & 16 & 3 subperiosteal elevation fxs (2 radius, 1 ulna) \\
7 & 1 & Female & Abused sibling & No & Not abuse & 18 & 7 ribs fxs*
\end{tabular}

$\mathrm{fx}(\mathrm{s})=$ fracture $(s)$

No new fxs = ISS only identified previously recognized fractures, which are listed under the 'reason for the ISS'

*The number of rib fractures has been specified in this table to show the extent of injuries identified on the FSS in these 8 subjects. In the remaining data collection for this study, multiple rib fractures counted as a single fracture. 


\section{DISCUSSION}

This is the largest study to date to assess the use of the FSS in children with suspected physical abuse. Unlike previous studies which only included patients in whom the diagnosis of abuse was strongly suspected before the FSS and/or patients who already had one or more fractures identified on ISS, our study included all patients who underwent both an ISS and FSS. Therefore, the lower proportion of positive FSS in our sample is likely more representative of the true rate than rates observed in previous studies. ${ }^{17,19,21}$

The Zimmerman and colleagues' recommendation that all patients who undergo an ISS should also get an FSS was published in late 2005. We therefore expected to see and did see an increase in the proportion of children who underwent both ISS and FSS after this time.

USE OF FOLLOW-UP SKELETAL SURVEY IN DIAGNOSIS OF CHILD PHYSICAL ABUSE

Children with a definite diagnosis of abuse after ISS routinely undergo FSS for reasons other than to identify new fractures (e.g. to make sure injuries are healing properly, to delineate the age of injuries). The major point of this study was to evaluate how the FSS influenced the diagnosis of abuse in children who did not have a previous definite diagnosis. In these children, a clinician, when deciding to obtain a FSS, had to compare the risks and benefits of a FSS. The primary risk of obtaining a FSS is radiation. However, there are also logistical barriers to obtaining a FSS 
which should be considered. Arranging for a child to return to the hospital for a FSS can be difficult if the patient is in foster care or in the care of the parent being investigated as the possible perpetrator. The benefits of obtaining a FSS are (1) being able to make a definite diagnosis of abuse and (2) preventing repeated injury in select cases. In the current study, the findings of the FSS were critical in making a definite diagnosis of abuse in $7.6 \%$ of the subjects without a previous diagnosis. Whether this proportion justifies the benefits over the risks of obtaining a FSS is a matter for future studies.

The 7 subjects in whom the FSS led to a definite diagnosis of abuse were all less than 12 months of age and the time interval between when the subjects underwent ISS and FSS was greater than 14 days in each case. These data suggest that clinicians should obtain a FSS in children who do not have a previous definite diagnosis of abuse even if the time interval between ISS and FSS is greater than the two week AAP recommendation. Among these 7 subjects, 3 had a negative ISS. Two of the 3 subjects had multiple bruises, which were the reason for ISS. One of the 3 subjects had no physical findings; she received an ISS because she was a contact child (she was in contact with her abused twin).

\section{EVALUATION OF EQUIVOCAL FRACTURES ON FOLLOW-UP SKELETAL SURVEY}

An important role of the FSS is to evaluate equivocal fractures and to confirm them as either normal variants or definite fractures. In our study, neither of these situations had a significant influence on the clinical diagnosis of abuse. There were a total of 32 equivocal fractures on ISS. A small portion of these equivocal findings were confirmed as definite fractures on FSS. 
However, a much larger portion was confirmed to be normal variants. Since fractures are common in physical abuse cases, radiologists are likely to be more sensitive to unusual findings and are more likely to interpret them as equivocal fractures when evaluating children with suspected abuse. Our results demonstrate that the type of fracture which was most likely to be 'over-read' was a metaphyseal fracture, which is highly specific for abuse. ${ }^{4-8}$ This presents an unusual problem for clinicians and radiologists that have to read the ISS in children suspected of physical abuse: missing a metaphyseal fracture could lead to mistakenly discharging a child into a dangerous environment. 'Over-reading' an unusual finding in the extremities as a metaphyseal fracture is a safeguard against this problem. An 'over-read' of the ISS in children suspected of physical abuse will encourage clinicians to obtain a FSS, upon which the equivocal findings can be reassessed.

THE POTENTIAL USE OF FOLLOW-UP SKELETAL SURVEY IN CONTACT CHILDREN

In our study, there was a single contact child with a negative ISS and no stigmata of abuse in whom the FSS demonstrated multiple rib fractures and led to a definite diagnosis of abuse.

Previous literature suggests that contact children are at an increased risk of abuse. ${ }^{31-37}$ In a related study at CHP that retrospectively assessed the use of the ISS in children with suspected physical abuse, 2 of 32 contact children who underwent an ISS had a positive ISS. The contact child in the current study was also part of the cohort of 32 contact children in the related study. ${ }^{30}$ Thus, 9.4\% (3/32) of contact children had either a positive ISS or a positive FSS. These data suggest that an FSS may be warranted in contact children even when the ISS is negative. 
This study had several limitations. Most importantly, although we evaluated all patients who underwent both ISS and FSS, there was still selection bias. The only patients who undergo FSS at CHP are those evaluated by the CPT. Thus children who have a negative ISS who do not obtain a consultation from the CPT do not get a FSS. Thus only patients in whom the treating physician obtains a CPT consult have the possibility of undergoing a FSS. The one exception is contact children who are evaluated by the CPT even if they have no stigmata of abuse. As a result, it is not possible to know the true rate of positive FSS. The fact that this study was retrospective is also a limitation, although performing this type of study prospectively would require parental consent and therefore would likely introduce a significant enrollment bias.

\section{FUTURE RESEARCH}

Future studies should compare children who only receive an ISS with those who receive an ISS and FSS. This type of comparison could help identify certain clinical characteristics that, when present in a child undergoing an ISS, should warrant a FSS. Future studies should assess the use of the FSS in contact children. The findings of such a study could be useful in establishing clinical practices to assess contact children by encouraging the use of the ISS and FSS in these select cases. There currently exists no national policy detailing the evaluation and medical management of contact children. ${ }^{37}$ 


\section{CONCLUSION}

The FSS is an important part of the clinical evaluation of suspected child physical abuse. The FSS identified new fractures which led to a definite diagnosis of abuse in $\sim 8 \%$ of subjects without a previous diagnosis of abuse. Future research should attempt to identify clinical characteristics that, when present in a child undergoing an ISS, suggest that the child should also undergo a FSS. 


\section{APPENDIX A}

\section{DEMOGRAPHICS AND INITIAL SKELETAL SURVEY DATA COLLECTION FORM}

First Name: Last Name:

MRN:

DOB:

DOSS1:

SEX

$1 \quad$ Male

$2 \quad$ Female

REASSKEL 1 recognized fracture - looking for others (i.e. single fx diagnosed first)

2 features of child abuse noted (e.g. head injury, bruises)

3 looking for fractures - symptomatic: sx or signs of trauma

$4 \quad$ looking for fractures - non-specific symptoms

5 asymptomatic/ social concerns (sibs, report of adult, CYF request, etc)

6 Other

7 ALTE

8 death

MOREINFO (select only 1 response)

\begin{tabular}{|c|c|c|c|c|}
\hline If \# 1 & If \# 2 & If \#3 & If \#4 & If \#5 \\
\hline $1 \mathrm{rib}$ & 1 bruise/bruises & $1 \downarrow$ use/moving & 1 fussiness & $1 \mathrm{sib} /$ contact \\
\hline 2 skull & 2 head injury & 2 swelling & $2 \downarrow$ sleep & 2 danger envir \\
\hline 3 upper ext (not hand) & 3 burns, other skin & 3 bruising & $3 \downarrow$ activity & 3 CPS request \\
\hline 4 lower ext (not feet) & 4 FTT & 4 other & 4 GI(vomit) & 4 Family reques \\
\hline 5 femur & 5 sexual abuse & 5 pain & 5 other & 5 other \\
\hline 6 hand/feet/spine & 6 other & & & 6 assault witnessed \\
\hline 7 other & $\begin{array}{l}7 \wedge \text { OFC } \\
8 \text { abnormal eye exan }\end{array}$ & & & 7 neglect/abandonmen \\
\hline $\begin{array}{ll}\text { SS1RESULT } & 0 \\
1\end{array}$ & $\begin{array}{l}\text { suspected fx only } \\
\text { no fx }\end{array}$ & & & \\
\hline
\end{tabular}


2 no fx, other than initial fx dx pre-survey (use only if \#1 in REASSKEL)

3 fracture(s) possible

4 fracture(s) definite

5 some definite, some possible

SS1ABNORM1

1 rib (s) (ribs count as 1fracture if likely to be caused by single event; $>2$ fxs if_different ages )

2 single fracture: skull

3 single fracture: upper extremity (not incl hands)

4 single fracture: lower extremity (not incl feet)

5 single fracture: other (e.g. hand, foot, spine)

6 two separate fractures

7 three fractures

8 four fractures

9 more than 4 fractures

10 single fracture: clavicle

$\begin{array}{lll}\text { SS1ABNORMSTATUS } & 1 & \begin{array}{l}\text { acute } \\ \text { healing/not acute (skull fractures without STS go here) } \\ \text { both acute and healing } \\ \text { unknown/ can't tell }\end{array} \\ & 3 & \\ \text { REPEATSS } & 1 & \text { Not done } \\ \text { Abuse ED } & 1 & \text { No } \\ & 2 & \text { Yes - definite } \\ & 3 & \text { Significant concern } \\ 4 & \text { Slight concern } \\ 5 & \text { Unknown - not enough info } \\ 6 & \text { No findings, but social concerns }\end{array}$

\section{Variables Defines}

\begin{tabular}{|l|l|}
\hline Variable & Label \\
\hline STUDYID & Study ID \\
\hline MRN & MRN \\
\hline DOB & Date of Birth \\
\hline DOSS & Date of SS \\
\hline year & <none> \\
\hline AGE & Age in months at time of SS \\
\hline SEX & Sex \\
\hline ARRIVAL & Mode of arrival at CHP \\
\hline
\end{tabular}




\begin{tabular}{|l|l|}
\hline REASHOSP & Initial reason for seeking medical attention \\
\hline REASSKEL & Primary Reason for SS \\
\hline MOREINFO & more information about reason for SS \\
\hline SS1RESULT & Result of initial SS \\
\hline SS1ABNORM & Abnormalities on initial SS (only if 3,4,5 above) \\
\hline SS1ABNORMSTATUS & $\begin{array}{l}\text { Status of abnormalities on initial skeletal } \\
\text { survey: }\end{array}$ \\
\hline HBVALUE & Hb \\
\hline PLATELETVALUE & Platelet \\
\hline ALKPHOSVALUE & alk phos \\
\hline CPK & CPK \\
\hline HEADCTRESUL & Head CT \\
\hline MRI & MRI \\
\hline repeatss & Repeat skeletal survey \\
\hline SS2ABNORMSTATUS & $\begin{array}{l}\text { Location of new abnormalities on repeat skeletal } \\
\text { survey - only fill out if \#3 above }\end{array}$ \\
\hline abuseed & abuse or not: assessment at the time \\
\hline location & Location \\
\hline ID2 & Study ID \\
\hline researchassistant & research person filling in data \\
\hline NOTES & Notes \\
\hline
\end{tabular}




\section{APPENDIX B}

\section{FRACTURES ON ISS AND FSS DATA COLLECTION FORM}

First Name:

MRN:
Last Name:

DOSS1:

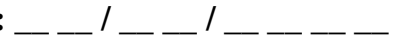

Was the reason for initial SS a previously recognized fracture? $\quad 1 \quad$ No $\quad 2$ Yes PREVFXLOC PREVFXTYPE Acute(1) Healing(2) Unknown(3)
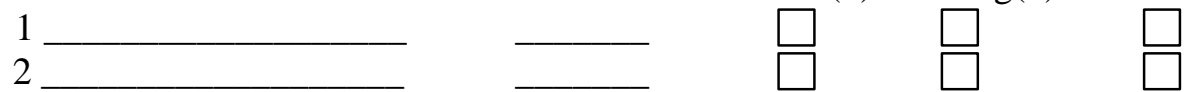

ISSFX

$3 \quad$ Normal (no fracture (s) on initial SS)

4 Only fracture(s) identified were those already recognized/suspected (see above)

5 Single rib: posterior/PL

6 Single rib: anterior/AL

$7 \quad$ Multiple ribs

8 Single fracture: skull

9 Single fracture: humerus

10 Single fracture: radius/ulna

11 Single fracture: femur

12 Single fracture: tibia/fibula

13 Single fracture: other (e.g. hand, foot, spine, clavicle)

14 More than one fracture

15 More than six fractures

FXTYPE

1 Transverse/greenstick

2 Spiral/oblique

3 Subperiosteal elevation

$4 \quad$ Metaphyseal

5 Buckle 
SEPERATEFXS SEPFXLOC SEPFXTYPE Definite(1)Possible(2)Acute(1)Healing(2)Unknown(3)

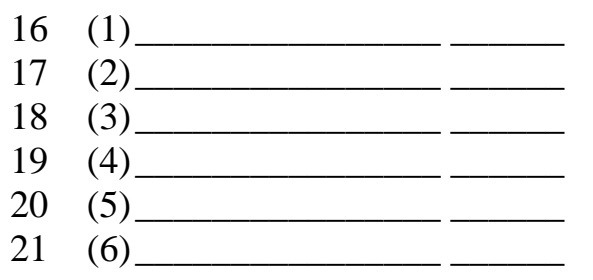

DOFSS: ' '

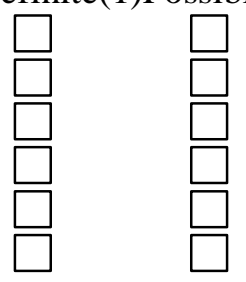

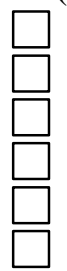

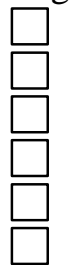

FSS

TIMEAFTERISS:

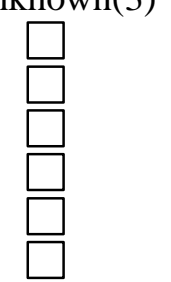

SS2CONFLICT

1 Specific fracture(s) no longer visible, list below (use \#1-21 from INITIALSSABNORML and MULTIPLESEPERATEFXS):
(1)
(2)
(3)
(4)
(5)
2 ALL skeletal findings from initial SS are no longer visible on repeat SS

\section{SS2NFX}

NFXTYPE
Single rib: posterior/PL Single rib: anterior/AL Multiple ribs

Single fracture: skull Single fracture: humerus Single fracture: radius/ulna Single fracture: femur Single fracture: tibia/fibula Single fracture: other

10 More than one fracture

11 More than six fractures

1 Transverse/greenstick

2 Spiral/oblique

3 Subperiosteal elevation

4 Metaphyseal

5 Buckle

6 Unknown/other
Definite(1) Possible(2) Acute(1) Healing(2) Unknown(3)
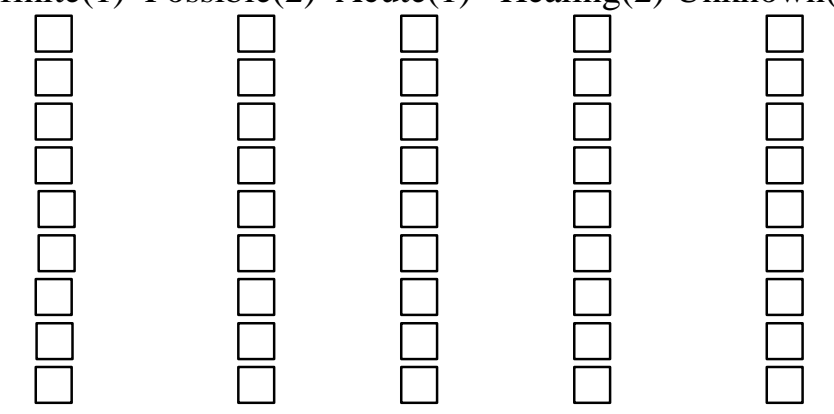

NSEPERATEFXS

NSEPFXLOC NSEPFXTYPE Definite(1)Possible(2)Acute(1)Healing(2)Unknown(3)

12
13
14

12

14
(1)
(2)
(3)
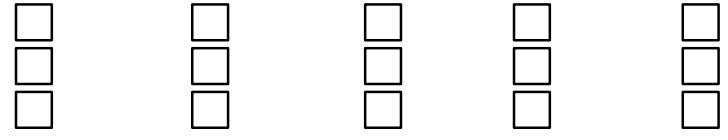
15 (4)

$16 \quad(5)$

17 (6)

What additional information did the f/up SS provide about the diagnosis of abuse?

$1 \quad$ None. Level of concern about abuse unchanged by f/up SS

2 Newly recognized fractures contributed to ability to make abuse $\mathrm{dx}$

3 Some fractures no longer visible. As a result, level of concern for abuse lower

4 Other, describe:

NOTES:

Variables Defines

\begin{tabular}{|l|l|}
\hline Variable & Label \\
\hline STUDYID & Study ID \\
\hline MRN & Medical Record Number \\
\hline DOB & Date of Birth \\
\hline DOSS1 & Date of Initial SS \\
\hline YEAR & <none> \\
\hline AGE & Age in months at time of SS1 \\
\hline SEX & Sex \\
\hline REASSKEL & Reason for Initial SS \\
\hline MOREINFO & more information about reason for SS \\
\hline PREVFX & Was there a previously recognized fracture? \\
\hline PREVFX1LOC & Previously recognized fx 1 location \\
\hline PREVFX1TYPE & Previously recognized fx 1 type \\
\hline PREVFX1STATUS & Previously recognized fx 1 status \\
\hline PREVFX2LOC & Previously recognized fx 2 location \\
\hline PREVFX2TYPE & Previously recognized fx 2 type \\
\hline PREVFX2STATUS & Previously recognized fx 2 status \\
\hline SS1RESULT & Result of Initial SS (definite and possible) \\
\hline SS1FXVISIBLE & $\begin{array}{l}\text { Visiblity of single or multiple fxs on intial } \\
\text { SS }\end{array}$ \\
\hline SS1ABNORMSTATUS & $\begin{array}{l}\text { Status of abnormalities on initial skeletal } \\
\text { survey }\end{array}$ \\
\hline FXTYPE & Long bone fracture type \\
\hline SEPFX1LOC & Multiple separate fx 1 location \\
\hline
\end{tabular}




\begin{tabular}{|c|c|}
\hline SEPFX1TYPE & Multiple separate fx 1 type \\
\hline SEPFX1VISIBLE & Multiple separate fx 1 visibility \\
\hline SEPFX1STATUS & Multiple separate fx 1 status \\
\hline SEPFX2LOC & Multiple separate fx 2 location \\
\hline SEPFX2TYPE & Multiple separate fx 2 type \\
\hline SEPFX2VISIBLE & Multiple separate fx 2 visibility \\
\hline SEPFX2STATUS & Multiple separate fx 2 status \\
\hline SEPFX3LOC & Multiple separate fx 3 location \\
\hline SEPFX3TYPE & Multiple separate fx 3 type \\
\hline SEPFX3VISIBLE & Multiple separate fx 3 visibility \\
\hline SEPFX3STATUS & Multiple separate fx 3 status \\
\hline SEPFX4LOC & Multiple separate fx 4 location \\
\hline SEPFX4TYPE & Multiple separate fx 4 type \\
\hline SEPFX4VISIBLE & Multiple separate fx 4 visibility \\
\hline SEPFX4STATUS & Multiple separate fx 4 status \\
\hline SEPFX5LOC & Multiple separate fx 5 location \\
\hline SEPFX5TYPE & Multiple separate fx 5 type \\
\hline SEPFX5VISIBLE & Multiple separate fx 5 visible \\
\hline SEPFX5STATUS & Multiple separate fx 5 status \\
\hline SEPFX6LOC & Multiple separate fx 6 location \\
\hline SEPFX6TYPE & Multiple separate fx 6 type \\
\hline SEPFX6VISIBLE & Multiple separate fx 6 visible \\
\hline SEPFX6STATUS & Multiple separate fx 6 status \\
\hline AbuseED & Assessment of abuse at time of SS1 \\
\hline DOSS2 & Date of repeat SS \\
\hline TIMEAFTERSS1 & Time (in days) between SS1 and SS2 \\
\hline SS2 & Result of repeat SS \\
\hline SS2CONFLICT & $\begin{array}{l}\text { Old fracture (s) no longer visible on repeat } \\
\text { SS }\end{array}$ \\
\hline CONFLICTFX1 & Fracture 1 no longer visible (1-21) \\
\hline CONFLICTFX2 & Fracture 2 no longer visible (1-21) \\
\hline CONFLICTFX3 & Fracture 3 no longer visible (1-21) \\
\hline CONFLICTFX4 & Fracture 4 no longer visible (1-21) \\
\hline SS2NFX & New recognized fracture(s) \\
\hline NFXVISIBLE & New fracture visibility \\
\hline NFXSTATUS & New fracture status \\
\hline NFXTYPE & New fracture type \\
\hline NSEPFX1LOC & New multiple separate fx 1 location \\
\hline NSEPFX1TYPE & New multiple separate fx 1 type \\
\hline
\end{tabular}




\begin{tabular}{|c|c|}
\hline NSEPFX1VISIBLE & New multiple separate fx 1 visibility \\
\hline NSEPFX1STATUS & New multiple separate fx 1 status \\
\hline NSEPFX2LOC & New multiple separate fx 2 location \\
\hline NSEPFX2TYPE & New multiple separate fx 2 type \\
\hline NSEPFX2VISIBLE & New multiple separate $\mathrm{fx} 2$ visiblity \\
\hline NSEPFX2STATUS & New multiple separate $\mathrm{fx} 2$ status \\
\hline NSEPFX3LOC & New multiple separate fx 3 location \\
\hline NSEPFX3TYPE & New multiple separate fx 3 type \\
\hline NSEPFX3VISIBLE & New multiple separate fx 3 visibility \\
\hline NSEPFX3STATUS & New multiple separate fx 3 status \\
\hline NSEPFX4LOC & New multiple separate fx 4 location \\
\hline NSEPFX4TYPE & New multiple separate fx 4 type \\
\hline NSEPFX4VISIBLE & New multiple separate fx 4 visiblity \\
\hline NSEPFX4STATUS & New multiple separate fx 4 status \\
\hline NSEPFX5LOC & New multiple separate fx 5 location \\
\hline NSEPFX5TYPE & New multiple separate fx 5 type \\
\hline NSEPFX5VISIBLE & New multiple separate fx 5 visiblity \\
\hline NSEPFX5STATUS & New multiple separate fx 5 status \\
\hline NSEPFX6LOC & New multiple separate fx 6 location \\
\hline NSEPFX6TYPE & New multiple separate fx 6 type \\
\hline NSEPFX6VISIBLE & New multiple separate fx 6 visibility \\
\hline NSEPFX6STATUS & New multiple separate fx 6 status \\
\hline NFXVISIBLEHS & $\begin{array}{l}\text { Were new skeletal findings visible in } \\
\text { hindsight }\end{array}$ \\
\hline FXVISIBLEHS1 & New fx 1 visible in hindsight \\
\hline FXVISIBLEHS2 & New fx 2 visible in hindsight \\
\hline FXVISIBLEHS3 & New fx 3 visible in hindsight \\
\hline ADDINFOSS2 & $\begin{array}{l}\text { What additional info. did the follow-up SS } \\
\text { provide }\end{array}$ \\
\hline NOTES & $\begin{array}{l}\text { Describe "other" from } \\
\text { ADDITIONALINFOSS2 }\end{array}$ \\
\hline
\end{tabular}




\section{BIBLIOGRAPHY}

1. U.S. Department of Health and Human Services Association of Children Y, and Families. Child Maltreatment 2007. Washington, D.C.: U.S. Government Printing Office; 2009.

2. Kempe CH, Silverman FN, Steele BF, Droegemueller W, Silver HK. The battered-child syndrome. JAMA. Jul 7 1962;181:17-24.

3. Leventhal JM, Martin KD, Asnes AG. Incidence of fractures attributable to abuse in young hospitalized children: results from analysis of a United States database. Pediatrics. Sep 2008;122(3):599-604.

4. Nimkin K, Kleinman PK. Imaging of child abuse. Radiol Clin North Am. Jul 2001;39(4):843-864.

5. King WK, Kiesel EL, Simon HK. Child abuse fatalities: are we missing opportunities for intervention? Pediatr Emerg Care. Apr 2006;22(4):211-214.

6. Kleinman PK. Diagnostic imaging in infant abuse. AJR Am J Roentgenol. Oct 1990;155(4):703-712.

7. Loder RT, Bookout C. Fracture patterns in battered children. J Orthop Trauma. $1991 ; 5(4): 428-433$.

8. Merten DF, Radkowski MA, Leonidas JC. The abused child: a radiological reappraisal. Radiology. Feb 1983;146(2):377-381. 
9. Oral R, Yagmur F, Nashelsky M, Turkmen M, Kirby P. Fatal abusive head trauma cases: consequence of medical staff missing milder forms of physical abuse. Pediatr Emerg Care. Dec 2008;24(12):816-821.

10. Nimkin K, Spevak MR, Kleinman PK. Fractures of the hands and feet in child abuse: imaging and pathologic features. Radiology. Apr 1997;203(1):233-236.

11. Diagnostic imaging of child abuse. Pediatrics. May 2009;123(5):1430-1435.

12. Merten DF, Carpenter BL. Radiologic imaging of inflicted injury in the child abuse syndrome. Pediatr Clin North Am. Aug 1990;37(4):815-837.

13. Belfer RA, Klein BL, Orr L. Use of the skeletal survey in the evaluation of child maltreatment. Am J Emerg Med. Mar 2001;19(2):122-124.

14. Day F, Clegg S, McPhillips M, Mok J. A retrospective case series of skeletal surveys in children with suspected non-accidental injury. J Clin Forensic Med. Feb 2006;13(2):5559 .

15. Spevak MR, Kleinman PK, Belanger PL, Primack C, Richmond JM. Cardiopulmonary resuscitation and rib fractures in infants. A postmortem radiologic-pathologic study. JAMA. Aug 24-31 1994;272(8):617-618.

16. Kleinman PK, Marks SC, Jr., Richmond JM, Blackbourne BD. Inflicted skeletal injury: a postmortem radiologic-histopathologic study in 31 infants. AJR Am J Roentgenol. Sep 1995;165(3):647-650.

17. Kleinman PK, Nimkin K, Spevak MR, et al. Follow-up skeletal surveys in suspected child abuse. AJR Am J Roentgenol. Oct 1996;167(4):893-896.

18. Diagnostic imaging of child abuse. Pediatrics. Jun 2000;105(6):1345-1348. 
19. Zimmerman S, Makoroff K, Care M, Thomas A, Shapiro R. Utility of follow-up skeletal surveys in suspected child physical abuse evaluations. Child Abuse Negl. Oct 2005;29(10):1075-1083.

20. Block RW. Follow-up skeletal surveys prove to be valuable in evaluation of child physical abuse. Child Abuse Negl. Oct 2005;29(10):1073-1074.

21. Harlan SR, Nixon GW, Campbell KA, Hansen K, Prince JS. Follow-up skeletal surveys for nonaccidental trauma: can a more limited survey be performed? Pediatr Radiol. Sep 2009;39(9):962-968.

22. Levi BH, Brown G. Reasonable suspicion: a study of Pennsylvania pediatricians regarding child abuse. Pediatrics. Jul 2005;116(1):e5-12.

23. Levi BH, Brown G, Erb C. Reasonable suspicion: a pilot study of pediatric residents. Child Abuse Negl. Apr 2006;30(4):345-356.

24. Levi BH, Loeben G. Index of suspicion: feeling not believing. Theor Med Bioeth. 2004;25(4):277-310.

25. ACR Practice Guideline for Skeletal Surveys in Children. Reston; VA. 2006.

26. Hansen KK, Harlan SR, Campbell KA. The Follow-up Skeletal Survey - Can We Maintain Sensitivity While Limiting the Views? Salt Lake City: University of Utah; 2009.

27. Berger RP, Adelson PD, Richichi R, Kochanek PM. Serum biomarkers after traumatic and hypoxemic brain injuries: insight into the biochemical response of the pediatric brain to inflicted brain injury. Dev Neurosci. 2006;28(4-5):327-335.

28. Berger RP, Dulani T, Adelson PD, Leventhal JM, Richichi R, Kochanek PM. Identification of inflicted traumatic brain injury in well-appearing infants using serum 
and cerebrospinal markers: a possible screening tool. Pediatrics. Feb 2006;117(2):325332.

29. Keenan HT, Runyan DK, Marshall SW, Nocera MA, Merten DF, Sinal SH. A population-based study of inflicted traumatic brain injury in young children. JAMA. Aug $62003 ; 290(5): 621-626$.

30. Duffy S, Squires J, Fromkin J, Berger RP. Using the skeletal survey to screen for physical abuse: Analysis of 703 consecutive skeletal surveys. Pittsburgh: University of Pittsburgh; 2010.

31. Alexander R, Crabbe L, Sato Y, Smith W, Bennett T. Serial abuse in children who are shaken. Am J Dis Child. Jan 1990;144(1):58-60.

32. Campbell KA, Bogen DL, Berger RP. The other children: a survey of child abuse physicians on the medical evaluation of children living with a physically abused child. Arch Pediatr Adolesc Med. Dec 2006;160(12):1241-1246.

33. Campbell KA, Squires J, Cook LJ, Berger RP. Disparities in the medical examination of children in the home of a child with suspected physical abuse. Child Abuse Negl. Sep 2009;33(9):612-617.

34. Ellaway BA, Payne EH, Rolfe K, et al. Are abused babies protected from further abuse? Arch Dis Child. Sep 2004;89(9):845-846.

35. Hamilton-Giachritsis CE, Browne KD. A retrospective study of risk to siblings in abusing families. J Fam Psychol. Dec 2005;19(4):619-624.

36. Rivara FP. Physical abuse in children under two: a study of therapeutic outcomes. Child Abuse Negl. 1985;9(1):81-87. 
37. Vitale MA, Squires J, Zuckerbraun NS, Berger RP. Evaluation of the Siblings of Physically Abused Children: A Comparison of Child Protective Services Caseworkers and Child Abuse Physicians. Child Maltreat. Feb 102010. 